\title{
PENSAMENTO CRÍTICO NA FORMAÇÃO DO ENGENHEIRO
}

Carla Eliana Todero Ritter-cetodero@gmail.com

Centro Universitário UniFTEC

Rua Gustavo Ramos Sehbe, 107. Bairro Cinquentenário

CEP 95012-669 Caxias do Sul-RS

Neiva Larisane Kuyven-neivakuyven@acad.ftec.com.br

Centro Universitário UniFTEC

Rua Gustavo Ramos Sehbe, 107. Bairro Cinquentenário

CEP 95012-669 Caxias do Sul-RS

Luiz Henrique Dias Correa - luizcorrea@acad.ftec.com.br

Centro Universitário UniFTEC

Rua Gustavo Ramos Sehbe, 107. Bairro Cinquentenário

CEP 95012-669 Caxias do Sul-RS

Resumo: A habilidade de pensar criticamente, a fim de resolver problemas e atuar de forma consciente, cidadã e técnica na sociedade é definida no perfil do engenheiro, visando a formação de profissionais com capacidade na tomada de decisões mais assertivas. Nesse artigo, foram apresentadas algumas repostas aos questionamentos sobre o posicionamento de estudantes do primeiro semestre de diferentes cursos de Engenharia frente às buscas por informações, ao gerenciamento delas e a sua inferência na prática durante pandemia vivenciada no momento de redação deste. Verificou-se, no grupo estudado, que a busca por informações é criteriosa, o senso comum é questionado de modo tênue e ingênuo e a inferência do conhecimento está em processo de construção. Os estudantes da disciplina de Química apresentaram, no recorte desse trabalho, que o pensamento crítico em relação aos conhecimentos disseminados nos meios de comunicação confronta com o conhecimento científico. A defesa do uso de alguns materiais e de soluções de combate aos microrganismos foi fundamentada em pesquisas bibliográficas de fontes confiáveis, segundo os alunos. Isso fornece um olhar de que há critérios para a construção de um pensar mais reflexivo.

Palavras-chave: Habilidades. Competências. Pensamento Crítico. Formação de engenheiros. 


\section{INTRODUÇÃO}

A construção do conhecimento, muito mais do que a transmissão dele, se faz com a reflexão constante e com habilidades essenciais como a do pensamento crítico. Mudança de posturas pedagógicas dos professores e de seus respectivos sistemas de ensino associada às questões sociais, econômicas, políticas, ambientais despertam o questionamento sobre o aprender a ser engenheiro e as consequências decorrentes disso. Necessário para uma formação global, Facione (1990) define pensamento crítico a partir do relatório Delphi como: julgamento autorregulatório intencional que resulta de interpretação, análise, avaliação e inferência, assim como explicação de considerações evidenciais, conceituais, metodológicas, criteriológicas ou contextuais sobre o qual esse julgamento se baseia.

O perfil desejado do engenheiro, segundo a Resolução $\mathrm{n}^{\circ} 11$ (Brasil, 2002), é aquele com formação generalista, humana, ética, crítica e reflexiva na resolução de problemas e que envolve múltiplos saberes, tecnologia, informação e visão global dos processos onde está inserido. Mas, além do aparato tecnológico, as experiências pessoais, a intuição cognitiva, o raciocínio lógico e a curiosidade são fundamentais para o sucesso na resolução de problemas (GUZZO, 2018). Nas Diretrizes Curriculares Nacionais (2019) vigentes para o curso de engenharia, algumas mudanças são evidenciadas no sentido de requerer às IES a formação cidadã, com foco na visão sistêmica, resolução efetiva de problemas, ações colaborativas, conhecimento de bases tecnológicas, capacidade de empreender e aplicação de parâmetros multidisciplinares.

Para o desenvolvimento e aprimoramento dessa habilidade, destaca-se que um dos propósitos do ensino superior é capacitar os estudantes para responderem às incitações da sociedade na construção do conhecimento, no diálogo intercultural, na cidadania e na aprendizagem ao longo da vida. Por não ser natural e necessitar de estímulo, o pensar criticamente, independentemente de sua abordagem, carece de aperfeiçoamento no ensino superior (FRANCO et al, 2017). Os autores reforçam o desenvolvimento da habilidade afirmando que "o pensamento crítico requer um acolhimento em sala de aula, um ensino que seja explícito e deliberado, uma prática continuada, a referência a problemas da vida real e cotidiana dos estudantes, assim como um feedback personalizado e atempado."

Em se tratando do domínio cognitivo, pensar criticamente, segundo a Taxonomia de Bloom, envolve as seguintes categorias: lembrar, entende, aplicar, analisar, sintetiza e criar (LOPES et al, 2019). A importância do pensamento crítico na educação é defendida por Guzzo (2018), quando salienta:

Toma-se assim o pensamento crítico como uma ferramenta que auxilia as pessoas a decidirem em que acreditar e no que fazer. Um cenário um pouco distinto também é verdadeiro: a aplicação do pensamento crítico é relevante porque cria nas pessoas um escudo de ceticismo saudável que as ajuda a determinar quais asserções não merecem confiança e, por isso, devem ser rejeitadas (pelo menos provisoriamente). Esse papel de defesa intelectual é uma razão pela qual o pensamento crítico deve merecer consideração educacional, pois seus efeitos perpassam a vida individual, e podem ter um alcance mais amplo na sociedade.

Assim, o objetivo desse trabalho foi perceber como o pensamento crítico pode ser estimulado em estudantes ingressantes de cursos de Engenharia no Ensino Superior. 


\section{PROCEDIMENTO METODOLÓGICO}

A partir de um questionário online com orientações sobre a sua participação e objetivo, o grupo de 30 estudantes do primeiro semestre de cursos de Engenharia do Centro Universitário, que cursavam a disciplina de Química, foi convidado a responder 7 questões envolvendo temas relacionados a uma pandemia viral. A participação foi voluntária e 18 alunos retornaram com respostas.

As questões eram dissertativas, abertas, mas as respostas foram orientadas para que não houvesse consulta a outros materiais impressos ou virtuais. Os estudantes foram orientados a responderem a partir da sua experiência, conhecimento prévio e conceitos tratados na disciplina. Essa atividade representa um recorte das proposições de pensamento crítico realizada em uma aula no início do semestre e ao longo da disciplina ocorreram outras, não inseridas nesse artigo.

\section{RESULTADOS E DISCUSSÃO}

Habilidade de resolver problemas com sucesso e aplicabilidade faz parte do exercício de pensar criticamente, ou seja, agir sobre diferentes assuntos envolve interpretação, avaliação, análise, inferência e explanação. Questões de análise, por exemplo, faz o pensar sobre as informações relevantes para o entendimento de uma situação. Já as questões que envolvem avaliação, permitem que as informações possam ser agrupadas para identificar um problema, se há pontos fortes e fracos em cada situação.

A fim de perceber se os estudantes interpretavam como um problema a falta de credibilidade em algumas informações durante um período de uma pandemia, foram questionados com a seguinte proposição: Quais "razões" e "evidências" você considera essenciais na seleção de uma informação como verdadeira. Ou seja, quais razões o levam a aceitar como verdadeira uma proposição e quais evidências o fazem perceber da mesma forma? Algumas das respostas dos estudantes estão citadas:

- Primeiro que procuro identificar é a fonte, qual a sua relevância e compromisso com o que veicula. $\mathrm{O}$ segundo questionamento que faço geralmente é em relação aos dados. Analiso a forma que foram coletados e estão dispostos. Procuro qual linha de pensamento a conclusão segue (Aluno 1).

- Na verdade, sempre se deve procurar informações em órgãos oficiais como OMS, Ministério da Saúde, e verificar se realmente as informações tem sentido e comparar os dados (Aluno 2).

- Sempre verificar mais de uma fonte, usar as fontes mais renomadas, e se constar em mais que uma delas, confiar na veracidade do fato (Aluno 3).

- Organizações oficiais do governo, matérias científicas e programas de televisão acompanhados de pesquisa são as formas que uso para obter informação (Aluno 4).

Um aspecto importante observado nos relatos dos estudantes está relacionado à falácia do apelo à autoridade evidenciada na resposta com maior notoriedade, pode encobrir falhas na aquisição de conhecimento na área (Alunos 2 e 3). Já o aluno 1 analisa as informações e o aluno 4 , busca mais do que uma fonte, reforçando que o pensar criticamente inicia-se pela 
escolha. Os estudantes percebem que as fontes de informação são primordiais na busca por informações que posteriormente formam o aparato de conceitos para as ações diárias.

Dessa forma, ter maturidade intelectual, social e emocional para exercer nossas responsabilidades democráticas apropriadamente, para que não ocorra manipulação, é uma habilidade importante para os estudantes em nível superior. O pensamento crítico pode ser instigado com pequenas proposições, mas em intensidade crescente e de forma contínua, de modo a aprimorar as habilidades mais complexas (GUZZO, 2018). Esse aspecto pode ser verificado no relato do Aluno 3 que busca mais de uma fonte da mesma informação e acredita nelas, se aparecerem repetidamente. Nesse contexto, a repetição de informações passa a ser um critério de veracidade para o estudante, tornando-o vulnerável ao efeito de reprodução de informações errôneas.

A partir da primeira questão, os estudantes responderam: Como agente de divulgação do conhecimento em seus ambientes sociais, familiares e cooperativos (emprego), qual sua postura perante a era da desinformação?

Com essa questão, buscava-se verificar qual a inferência que os estudantes já realizavam em seus locais de trabalho e familiares a partir de um determinado assunto/conhecimento. Algumas das respostas obtidas, foram:

\begin{abstract}
- Infelizmente estamos presenciando o culto a ignorância. Isso já aconteceu outras vezes na história humana e foi superado. Rendendo a alguns, o título de déspota esclarecido ou abolicionista, mérito apenas por seu posicionamento. Na era da informação, que estamos vivendo, tendo a tecnologia e a informação acessíveis, o culto a ignorância parece imperar, mas não impera. Sim, todo dia são publicados conteúdos que parecem estar a serviço da desinformação, que parece informar. Este conteúdo está associado a um algoritmo de busca, que vai te indicar outras páginas similares. A proteção contra a influência de alguns conteúdos, pode ter valores e princípios bem claros. $O$ senso crítico para um questionamento mais abrangente deve existir. E cito o senso crítico como principal agente de combate a ignorância, por que o conteúdo com desinformação circula com muita facilidade entre o senso comum (Aluno 5).

- Sempre que alguém vem com uma informação que não faz muito sentido, peço de onde é a fonte da informação pois não tenho confiança na rede social, pois existe muita mentira no meio (Fake News), e a maioria espalha o que vê nas redes sociais sem pesquisar em órgãos oficiais (Aluno 2).

- Muitas informações chegam a nós todos os dias. Quando é um assunto de relevância, procuro pesquisar em sites e materiais de confiança (Aluno 6).
\end{abstract}

O questionamento ao senso comum (Aluno 5) está relacionado à comparação entre as diferentes fontes de conhecimento e o alerta de fontes de pesquisa que são questionáveis (Aluno 2). O aluno 5, segundo Facione (1990), apresenta a habilidade de interpretação, definida por "compreender e expressar o sentido ou significado de uma grande variedade de experiências, situações, dados, eventos, julgamentos, convenções, crenças, regras, procedimentos ou critérios". Pelo relato do Aluno 2, vivemos na era da desinformação, onde assimilar e avaliar a veracidade da grande quantidade de informação nos faz questionarmos as ideias de outras pessoas, nem as nossas próprias, não saberemos quais são as informações mais confiáveis a respeito de qualquer assunto (GUZZO, 2018).

A fim de verificar como o senso comum e o conhecimento científico estavam interligados na percepção dos alunos, eles responderam à seguinte proposição no contexto da pandemia de vírus, vivida durante a escrita desse artigo, onde as fontes de informações divulgavam, em massa, conteúdos e informações referentes aos produtos para higienização: $\mathrm{O}$ 
uso de solução de álcool e água no percentual de $70 \%$ é eficiente no controle populacional de agentes patogênicos como bactérias e vírus. Qual a fundamentação teórica que embasa essa afirmação?

A reposta a seguir ilustra o posicionamento dos estudantes, uma vez que contém elementos que justificam:

O álcool $70 \%$ possui concentração ótima para o efeito bactericida, porque a desnaturação das proteínas do microrganismo faz-se mais eficientemente na presença da água, pois esta facilita a entrada do álcool para dentro da bactéria e também retarda a volatilização do álcool, permitindo maior tempo de contato. Nesta concentração, o etanol destrói bactérias vegetativas, porém esporos bacterianos podem ser resistentes. Fungos e vírus também são destruídos pelo álcool (Aluno 5).

O pensar criticamente se faz também com a busca por elementos científicos na justificativa de uma escolha e também foi tema da questão: O uso do sabão (substância com regiões polares e apolares) é indicado para a assepsia de mãos e demais objetos de uso comum na prevenção de doenças. A partir de qual embasamento teórico seu uso foi indicado e hoje se tornou expoente de discussões científicas? Qual a justificativa científica para o uso do sabão como agente bactericida?

Como respostas, selecionou-se duas que apresentaram, mesmo que brevemente, a habilidade de avaliação, que segundo Facione (1990) consiste no processo de julgar a credibilidade das afirmações ou outras representações que são considerações ou descrições da percepção, experiência, situação, julgamento, crença ou opinião; e julgar a consistência lógica das relações inferenciais reais ou esperadas entre afirmações, descrições, questões ou outras formas de representação.

- O sabão possui uma função emulsificante, que ajuda a unir água e gorduras, e também permite a remoção mecânica tanto da sujeira quanto de micro-organismos. Isso quer dizer que ele é capaz de unir moléculas que normalmente não ficariam unidas, agindo como ponte para que elas sejam carregadas pela água. Em tempos de pandemia, o objetivo é tirar o máximo desses micróbios de circulação (Aluno 7).

- O sabão é um ótimo material para limpeza pessoal devido a sua composição (álcool, glicerina...) em que ao formar o composto e por ter suas partes apolares e polares, ele acaba se dissolvendo na água e dissolvendo substância apolares, consequentemente, matando germes, vírus e bactérias (Aluno 8).

Pode-se indicar uma proficiência iniciante na habilidade de avaliação, no contexto de relacionar conhecimento científico, no relato do Aluno 7, uma vez que apresentou razoável conhecimento para a resolução do problema com sucesso. Outra habilidade que caracteriza o pensamento crítico é a inferência, que é caracterizada como: identificar e assegurar os elementos necessários para elaborar conclusões racionais; elaborar conjecturas e hipóteses; considerar informações relevantes e inferir as consequências proveniente dos dados, afirmações, princípios, evidências, julgamentos, crenças, opiniões, conceitos, descrições, questões, ou outras formas de representação (FACIONE, 1990).

Nesse contexto, a inferência do conhecimento na realidade estava sendo questionada por diferentes meios de comunicação. Os estudantes foram convidados a responderem: Durante a pandemia do Coronavírus, indicou-se a confecção de máscaras de pano, tecido usado, geralmente para uso doméstico. Essa medida foi incentivada por diferentes esferas a fim de 
minimizar a proliferação do vírus. Você, como futuro engenheiro, como posiciona-se em relação a este assunto? Indicaria ou não o uso de máscaras feitas de tecido? Baseando-se em que critérios você formulou sua resposta?

\begin{abstract}
-Sim, deve-se usar máscara, até mesmo se estiver com algum tipo de gripe e morar sozinho, pois a cada espirro ou tosse os vírus ficam no ambiente em que você está alojado, prejudicando a próxima pessoa que passar por ali, evitando a propagação da doença, se todos não usarmos máscaras, aumentaríamos grandemente a propagação da doença, prejudicando outras pessoas (Aluno 9).

-Eu indico o uso de máscaras de tecido pela população, desde que ela seja bem produzida (duas ou mais camadas de tecido). Ela reduz os vetores de contaminação por meio de respiração e ainda dificulta o manuseio com a mão na face. Além de ajudar a obstruir a contaminação, a confecção de máscara de pano diminui a demanda por cirúrgicas, que são descartáveis e para um determinado público. Baseei-me para responder em torno das minhas ideias e aprendizados e sobre as matérias que vejo (Aluno 10).

-As máscaras de pano não protegem o usuário $100 \%$ contra o vírus, mas ajudam a impedir o usuário de transmitir o vírus (Aluno 11).

-Como pano impede parcialmente a passagem das vias aéreas, ele diminui a passagem de ar e saliva que podem estar infectados (Aluno 12).

-Na minha opinião, não concordo com as máscaras de tecido comum, pois não são testadas por nenhum órgão como o INMETRO e outros laboratórios. Já as máscaras cirúrgicas acredito que sejam eficazes, pois funcionam com um filtro de partículas (Aluno 13).

-Não acredito que o uso de máscaras de pano seja eficaz, pois o tecido possui muitos poros por onde poderiam passar os vírus e se proliferarem em diferentes ambientes (Aluno 14).
\end{abstract}

Observou-se que houve posicionamento por parte dos alunos em relação ao assunto em questão, entretanto somente o Aluno 14 definiu o critério para a emissão de parecer em relação ao uso de tecido na confecção de máscaras. O Aluno 10 também apresenta elementos que caracteriza a reflexão aliada à questão social e ao conhecimento e seleção de materiais. Apesar de frágil, a capacidade de pensar criticamente, evidenciada nos relatos dos estudantes, está sendo evidenciada.

Sem a pretensão de definir os processos do pensamento crítico, esse documento permite exemplificar que é possível propor momentos de pensamento e autonomia em qualquer etapa do fazer pedagógico no ensino superior, sem um protocolo definido, mas que o seja contínuo. Nesse sentido, o desenvolvimento de uma habilidade não acontece de forma abstrata e sem ter algo em que pensar; deve ter um caráter situado, que facilite a permanência e transferência para outros contextos (Lattorre Velaquez, 2018).

\title{
4 CONSIDERAÇÕES FINAIS
}

O pensamento crítico tem essencial papel na formação do engenheiro, pois é por meio de habilidades complexas, que melhores profissionais estarão atuando na sociedade. Independente da área de atuação do engenheiro, agir a partir de reflexões, análise, avaliação e inferências tornará segura a tomada de decisões, a argumentação, a gestão de conflitos e a avaliação imparcial de situações-problemas. Ciente que o aprimoramento do pensamento crítico no ensino superior se faz ao longo do curso, há a necessidade de estímulo à curiosidade intelectual e à construção do conhecimento. 
O perfil do estudante será atingido quando o pensar criticamente se fizer de modo contínuo, estimulando a tomada de decisões e a resolução de problemas. E é nesse desafio onde o papel do professor se encontra, como agente de questionamentos incansável, relacionando em pequenos momentos grandes momentos de reflexão.

\section{REFERÊNCIAS}

BRASIL. Conselho Nacional de Educação. Câmara de Educação Superior - CNS/CES. Resolução no 11 , de 11 de março de 2002. Institui Diretrizes Curriculares Nacionais do Curso de Graduação em Engenharia. Diário Oficial da República Federativa do Brasil, Brasília, DF, 2002.

BRASIL. RESOLUÇÃO No 2, DE 24 DE ABRIL DE 2019. Institui as Diretrizes Curriculares Nacionais do Curso de Graduação em Engenharia. Brasília, 2019.

FACIONE, N. Critical thinking: a statement of expert consensus for purposes of educational assessment and instruction. Millbrae, CA: The California Academic Press, 1990.

FRANCO, A.; VIEIRA R.M.; SAIZ,C. O pensamento crítico: as mudanças necessárias no contexto universitário. Revista de estudios e investigación en psicología y educaciónel, Aveiro, Vol. Extr., No. 07, 2017.

GUZZO, G.B. O pensar na educação: uma discussão sobre as implicações da psicologia cognitiva para o exercício do pensamento crítico. Tese apresentada na PUC-RS, 2018.

LATORRE VELÁSQUEZ, Diana Carolina. Avaliação De Argumentos No Ensino Superior: Transferência De Habilidades Da Sala De Aula a Situações Extracurriculares. Tese apresentada na Universidade Federal de Pernambuco, 2018.

LOPES, J.; SILVA, H.; MORAIS. E. Teste do Pensamento Crítico e Criativo para estudantes do ensino superior. Revista Lusófona de Educação, 44, 173-189. 2019. doi: 10.24140/issn.1645-7250.rle44.11

\section{CRITICAL THINKING IN ENGINEER TRAINING}

Abstract: The ability to think critically in order to solve problems and act in a conscious, citizen and technical way in society is one of those defined in the profile of the engineer in the search for professionals with the capacity to make assertive decisions. In this article, some answers to the questions about the positioning of students in the first semester of different Engineering courses were presented in the face of the search for information, their management and their inference in practice during the pandemic experienced at the time of writing. It was found in the studied group, that the search for information is judicious, common sense is questioned in a tenuous way and the inference of knowledge is in the process of construction. Chemistry students presented, in the context of this work, that critical thinking in relation to the knowledge disseminated in the media confronts scientific knowledge. The defense of the use of some materials and solutions to combat microorganisms was based on bibliographic research from reliable sources, according to the students. This provides a view that there are criteria for building more reflective thinking.

Keywords: skills, critical thinking, formation of engenieers. 
